\title{
Ha-ras and c-myc oncogene expression interferes with morphological and functional differentiation of mammary epithelial cells in single and double transgenic mice
}

\author{
Anne-Catherine Andres, Martin A. van der Valk, ${ }^{1}$ Cora-Ann Schönenberger, Franziska Flückiger, \\ Marianne LeMeur, ${ }^{2}$ Pierre Gerlinger, ${ }^{2}$ and Bernd Groner ${ }^{3}$ \\ Ludwig Institute for Cancer Research, Bern Branch, Inselspital, 3010 Bern, Switzerland; ${ }^{1}$ The Netherlands Cancer Institute, \\ 1066 CX Amsterdam, The Netherlands; ${ }^{2}$ Laboratoire de Génétique Moléculaire des Eucaryotes, Centre National de la \\ Recherche Scientifique, 67085 Strasbourg Cedex, France
}

\begin{abstract}
We studied the effects of the tissue-specific and lactogenic hormone-dependent expression of the recombinant whey acidic protein (Wap)-ras and Wap-myc oncogenes on the differentiation of the mammary epithelium in transgenic mice. The histological appearance of mammary glands in pregnant, lactating, and postlactational animals and their ability to express milk protein genes were analyzed. Activated Ha-ras expression caused a decrease of milk protein synthesis during the lactation period. The formation of glandular epithelium and the postlactational regression of epithelial cells were not affected. c-myc expression impaired the development of the glandular epithelium, and milk protein synthesis was decreased strongly. Epithelial cell proliferation continued during lactation and postlactationally. Coexpression of both oncogenes in double transgenic mice synergistically affected differentiation and resulted in a high number of neoplastic foci. Palpable tumors were observed only after a latency of 3-4 months. Tumor cells utilize the Wap promoter hormone independently, express increased levels of Wap-ras and induce adjacent stromal cells to produce tenascin.
\end{abstract}

[Key Words: Mammary adenocarcinomas; milk protein gene expression; oncogene cooperation; tenascin; whey acidic protein gene promoter]

Received June 6, 1988; revised version accepted September 9, 1988.

The mammary gland is a complex structure formed by parenchymal and mesenchymal cells. Its differentiation is dependent on hormonal status, and cell interactions are thought to be crucial for the development process (Baneriee 1976; Levine and Stockdale 1985). Interactions between the epithelial and the stromal components and extracellular matrix proteins, like tenascin, have been shown to be important (Kratochwil 1969; ChiquetEhrismann et al. 1986). Neoplastic diseases are considered to be the escape of the tumor cells from this complex growth control.

Activated oncogenes may contribute to carcinogenesis in the mammary gland. Amplification and overexpression of the c-erbB-2 gene have been found frequently in human breast tumors and are of prognostic value for the course of the disease (Slamon et al. 1987; Berger et al. 1988). Members of the ras gene family activated by point

${ }^{3}$ Corresponding author. mutations were detected in human mammary tumor cell lines (Kozma et al. 1987) and in chemically induced mammary adenocarcinomas in rodents (Zarbl et al. 1985). Amplification of the c-myc gene has been found in about one-third of human breast tumors (Escot et al. 1986; Varley et al. 1987).

Transgenic mice provide the means to investigate the role of oncogenes in carcinogenesis and development. The elastase promoter (Quaife et al. 1987), the immunoglobulin enhancer (Adams et al. 1985; Suda et al. 1987), and the long terminal repeat (LTR) of mouse mammary tumor virus (MMTV) (Stewart et al. 1984; Leder et al. 1986; Sinn et al. 1987) have been used to target the expression of the Ha-ras and c-myc oncogenes in transgenic mice. Tumor formation in the oncogene-expressing animals has revealed the specific transforming potential of each oncogene. Tumor formation did not coincide with the onset of oncogene expression, supporting the view of carcinogenesis as a multistep process. Tumor formation in vivo might require the simulta- 
neous activation of several cooperating oncogenes (Sinn et al. 1987).

The identification of proto-oncogenes as growth factors, growth factor receptors, signal transducers, and transcription factors indicates their importance in the control of cell growth and differentiation (Bishop 1985; Struhl 1987/. Therefore, their activation may affect differentiation before transformation becomes apparent. For example, v-ras expression in MMTV LTR-v-ras transgenic mice affects the proliferation of epithelial cells in the orbital Harderian gland (Sinn et al. 1987). Expression of the c-fos oncogene in transgenic mice specifically affects bone remodeling by favoring bone formation over resorption (Rüther et al. 1987). Deregulated c-myc expression in the lymphoid compartment led to over-representation of immature pre-B cells that preceded the development of lymphomas in transgenic mice (Langdon et al. 1986). Defects in the secondary lens fiber differentiation were the consequences of v-mos oncogene expression in the eye lens (Khillan et al. 1987).

Previously we described the mammary-gland-specific and hormone-dependent expression of the activated human Ha-ras and the murine c-myc oncogenes coupled to the murine whey acidic protein (Wap) gene promoter in transgenic mice. Whereas the Wap-ras gene displayed a low tumorigenic potential in the mammary epithelial cells (Andres et al. 1987), the Wap-myc transgenic females developed mammary adenocarcinomas with a high frequency (Schönenberger et al. 1988). To characterize the mechanism of c-myc and Ha-ras action, we have now begun an analysis of the effect of oncogene expression on cellular growth, differentiation, and interaction in the mammary gland. Because the Wap promoter is induced by lactogenic hormones during midpregnancy (Hobbs et al. 1982; S. Harris, pers. comm.), the effects of the oncogenes on a defined differentiation process can be investigated. Our studies reveal specific oncogene interference with histological and functional features of mammary gland differentiation, which precede tumor formation.

To investigate oncogene cooperation in vivo, we established mice bearing the Wap-ras and the Wap-myc genes. Animals carrying both transgenes have been termed double transgenics. Coexpression of both genes resulted in impairment of mammary gland function during lactation and hyperplastic growth of the epithelium. However, additional events are required to establish the fully malignant phenotype of the mammary epithelial cells, even in the presence of two activated oncogenes.

\section{Results}

\section{Establishment of double transgenic mice}

Because malignant transformation is a multistep process that might involve the activation of several cooperating oncogenes, we analyzed the synergistic effects of the Ha-ras and c-myc oncogenes in vivo. Double transgenic mice have been established by crossing single transgenic
Wap-ras and Wap-myc animals (Andres et al. 1987; Schönenberger et al. 1988!.

Double transgenic females were analyzed for the simultaneous expression of both transgenes. Cytoplasmic RNA was prepared from mammary glands at day 19 of pregnancy, at day 3 after parturition, or 4 weeks after lactation, and analyzed for Wap-ras and Wap-myc transcripts by RNase protection assays. To detect Wap-rasspecific sequences, an antisense probe indicative for exon 1 of the human Ha-ras gene was used. This probe protects a fragment of 133 nucleotides (Fig. 1A). The antisense probe used to detect Wap-myc RNA protects a fragment of 198 nucleotides, which is indicative for exon 1 of the Wap-myc gene (Fig. 1B). On day 19 of pregnancy, we detected low levels of Wap-ras and Wap-myc RNA in the mammary gland of double transgenic females (Fig 1, lanes 2). The levels of both Wap-ras and Wap-myc RNA were increased in mammary glands after parturition (Fig. 1, lane 3). The levels of transgene expression in lactating mammary glands of double transgenic females were comparable to those found in the single transgenic Wap-ras (Fig. 1A, lane 1) or Wap-myc females during lactation (Fig. 1B, lane 1). Wap-ras and Wap-myc RNA could not be detected in mammary glands of females after lactation (lanes 4) and in the other organs of lactating females (data not shown). The expression of both transgenes is regulated similarly to the expression of the endogenous Wap gene. All three genes were expressed in the mammary gland during pregnancy, increased in expression during lactation, and were silent after lactation.

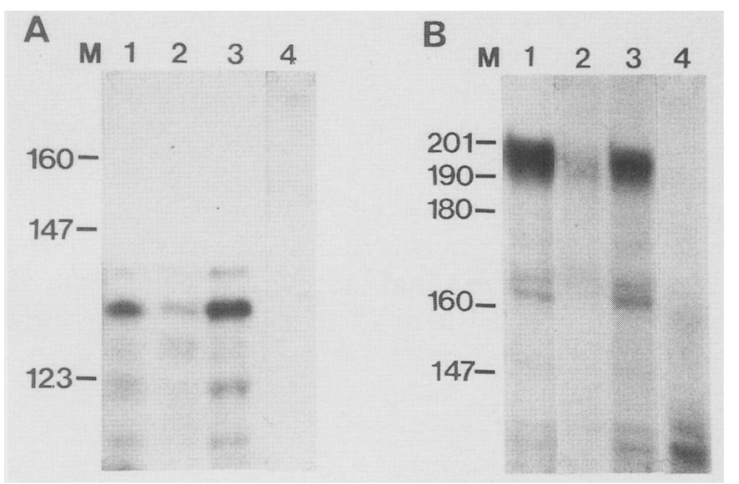

Figure 1. Coexpression of the Wap-myc and Wap-ras genes. Ten micrograms of cytoplasmic RNA was analyzed for Wapras-specific $(A)$ and Wap-myc-specific $(B)$ transcripts in RNase protection assays. (Lane 1) RNA from lactating mammary glands of a Wap-ras $(A)$ and a Wap-myc $(B)$ transgenic female. RNA from mammary glands of double transgenic females at end pregnancy (lane 2), during lactation (lane 3), and after lactation (lane 4). To detect Wap-ras-specific sequences, a probe indicative of exon 1 of the human Ha-ras was used, protecting a fragment of 133 nucleotides. Wap-myc RNA was detected with a probe protecting 198 nucleotides indicative for exon 1 of the Wap-myc gene. (M) HpaII-digested, ${ }^{32} \mathrm{P}$-end-labeled pBR322 DNA as size marker (indicated in nucleotides). 
Andres et al.

Oncogene expression affects the histological

differentiation and regression of the mammary epithelium

The Wap promoter is activated at mid-pregnancy, a time when cell proliferation and morphological differentiation take place. To define oncogene effects on these developmental processes, we compared the histological appearance of mammary tissue section of wild-type, Wapras, Wap-myc, and double transgenic animals at different stages of development.

Wild-type and transgenic animals did not differ in the appearance of the virgin mammary tissue (not shown). Pregnant animals were analyzed at day 19 or day 20 of gestation. During this time, the mammary fat pads of wild-type animals are occupied entirely by glandular tissue (Fig. 2A). Incomplete outgrowth of the glandular trees can be observed in Wap-ras transgenic animals (Fig. 2B) and is even more pronounced in the Wap-myc (Fig. 2C) and double transgenic animals (Fig. 2D).

Lactating mice were analyzed 10-14 days after parturition. Superficially, the wild-type and Wap-ras animals showed a similar appearance (Fig. 3A,B). Almost the entire fat pad was filled with glandular and ductal cells and cell proliferation ceased in these glands. Only subtle differences were found. Alveoli in Wap-ras animals seemed smaller and more numerous. The mutual compression of alveoli, characteristic of secretion, was less pronounced in Wap-ras-expressing glands. Focally, atypias in the epithelium such as increased cell volume, en- larged nuclei and nucleoli, and poor lateral cell contact could be detected. In lactating Wap-myc transgenic animals, epithelial cells did not fill the fat pads completely (Fig. 3C). In contrast to the Wap-ras and wild-type females, mitotic figures were found frequently. Dysplastic and hyperplastic epithelium was distributed uniformly in the tissue. The double transgenic animals were affected most severely with respect to tissue appearance during the lactation period (Fig. 3D). Only a limited development of the epithelium was observed. The glandular tree was severely underdeveloped and showed immature lobulo-alveolar units containing dysplastic and hyperplastic epithelium. Generally, structural changes seemed to affect entire locular units. Mitotic activity was commonly detected in the underdeveloped, mature, and hyperplastic alveoli and ductules. Only the epithelial cells of the main ducts did not show aberrant phenotypic features.

Distinct oncogene effects could also be seen postlactationally. Wild-type and transgenic animals were investigated 4 weeks after cessation of the lactogenic stimulus. The lobulo-alveolar part of the gland regressed and only the main ducts persist in wild-type animals (Fig. 4A). Normal regression of the lobulo-alveolar part was observed in Wap-ras animals (Fig. 4B). Moderate numbers of alveolar and 'bud-like' ductal structures with proliferating cells remained postlactationally in Wap-myc mammary glands (Fig. 4C). This escape from postlactational regression was more pronounced in double transgenic females. Numerous hyperplastic and neoplastic
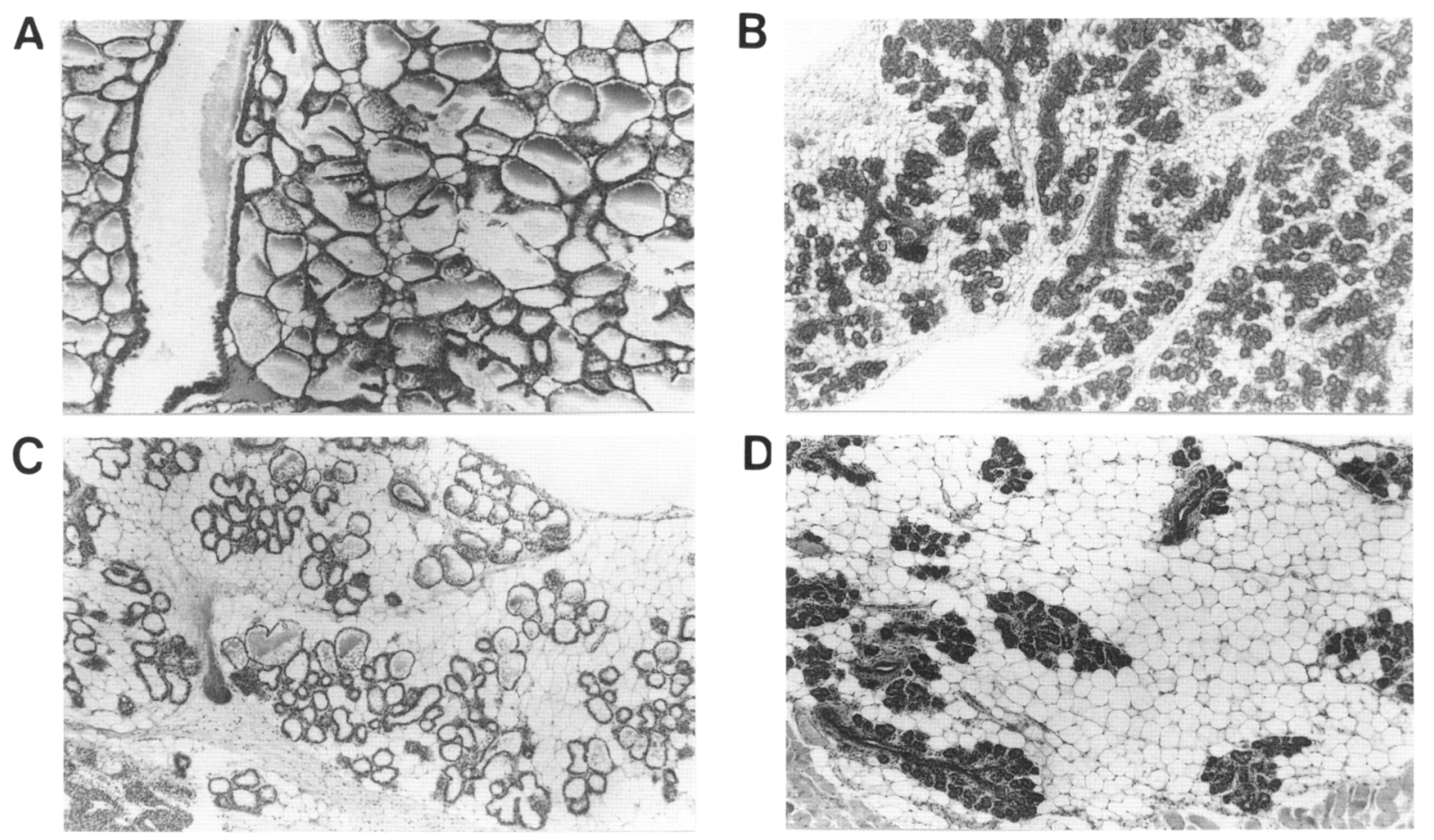

Figure 2. Histological appearance of the mammary glands at end pregnancy. Sections of mammary glands of a wild-type $(A)$, a Wap-ras $(B)$, a Wap-myc $(C)$, and a double transgenic female $(D)$. The sections were stained with hematoxylin-eosin. Magnification, $220 \times$. 
A

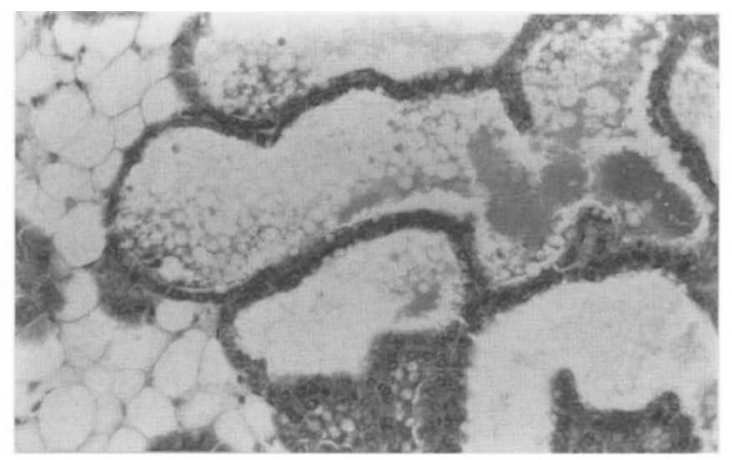

C

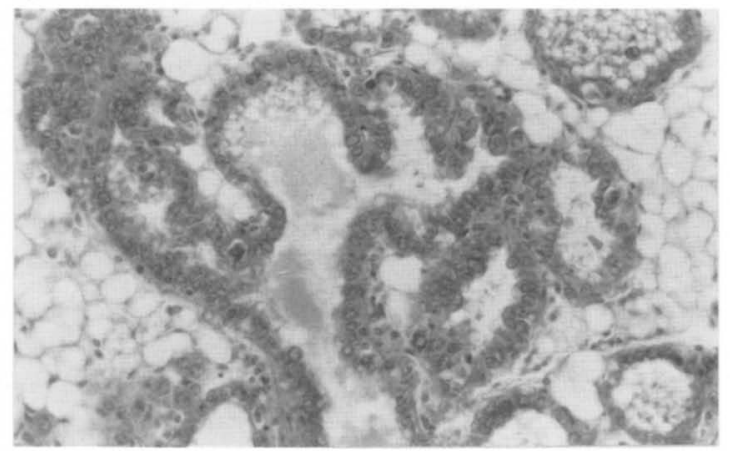

B

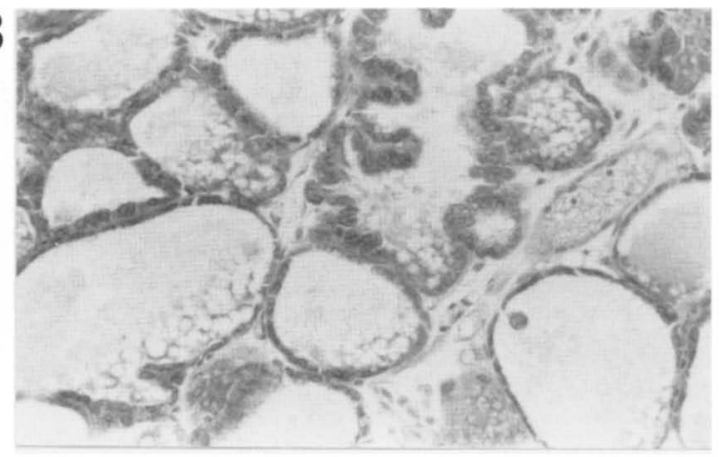

D

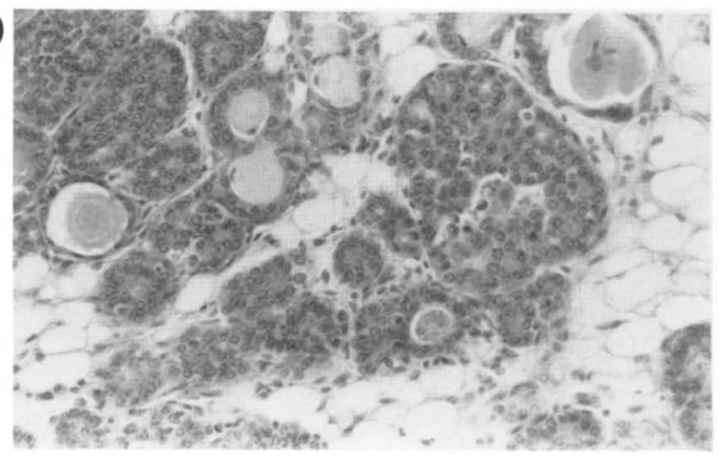

Figure 3. Histological appearance of the lactating mammary glands. Sections of mammary glands of a wild-type $(A \mid$, a Wap-ras $(B)$, a Wap-myc $(C)$, and a double transgenic female $(D)$. The sections were stained with hematoxylin-eosin. Magnification, $540 \times$.

lobulo-alveolar lesions could be observed (Fig. 4D). The number and appearance of these lesions varied among individuals but also within individual glands, and abnormalities increased with age and number of lactations of the animals. Intraductal, basaloid hyperplastic, as well as metaplastic, salivary gland-like hyperplasia with many mitoses could be detected.

We concluded that the Wap-ras and Wap-myc onco-

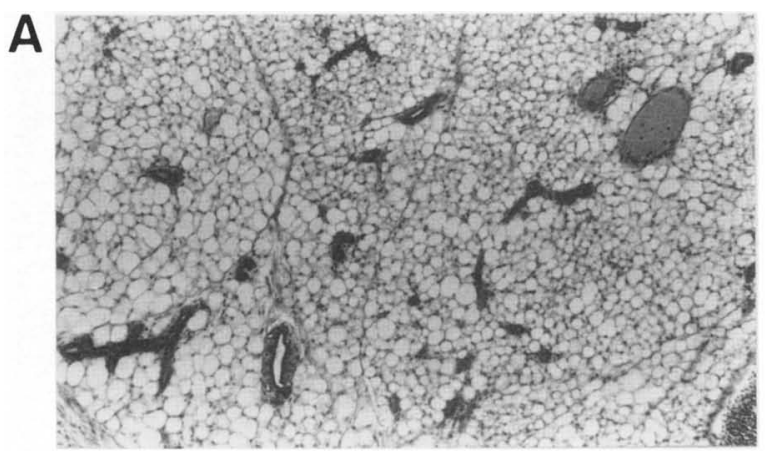

B
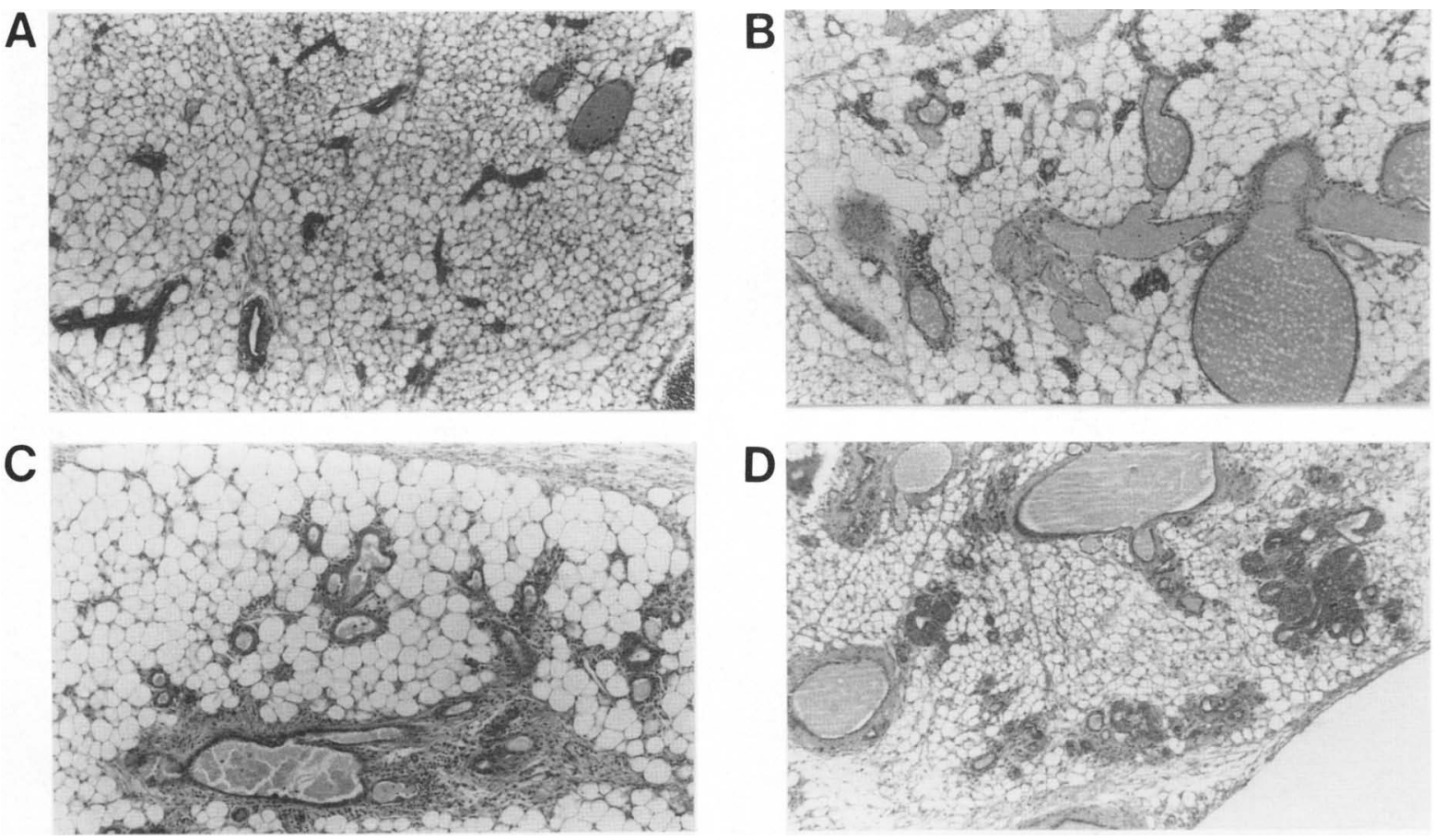

Figure 4. Histological appearance of the regressed mammary glands. Sections of mammary glands of a wild-type $(A)$, a Wap-ras $(B)$, a Wap-myc $(C)$, and a double transgenic female $\langle D|$. The sections were stained with hematoxylin-eosin. Magnification, $220 \times$. 
genes exert distinct effects on the differentiation of mammary epithelial cells. Whereas the Wap-ras oncogene does not seem to block the maturation of the cells, it interferes with the synthesis and secretion of milk components (see below). The Wap-myc oncogene inhibits the structural development and interferes with normal regression. Coexpression of both oncogenes together leads to a severely obstructed glandular organization, and preneoplastic lesions are observed with a high frequency in postlactational glands.

\section{Oncogene expression affects the function of the mammary epithelium}

Because oncogene expression affects the development and the organization of the mammary epithelium, we investigated the consequences on the expression of the differentiation-specific milk protein genes. Accumulation of $\beta$-casein and Wap mRNA was analyzed in mammary glands of end-pregnant and lactating transgenic animals (Fig. 5). The amount of $\beta$-casein mRNA at end pregnancy is similar to wild-type, Wap-ras, and Wapmyc animals (Fig. 5A, lanes $1-3$ ) but nearly undetectable in double transgenic mice (lane 4). The levels of $\beta$ casein mRNA increased during lactation in wild-type animals (Fig. 5, lane 5). This increase was not seen in the transgenic lines (lanes $6-8$ ). Compared to those in wildtype mice, reduced levels of Wap mRNA were found in the transgenic lines at end pregnancy (Fig. 5B, lanes $1-4)$. During lactation, the level of Wap RNA increased in the wild-type mice (lane 5) and, to a lesser extent, in the Wap-ras transgenic females (lane 6). In Wap-myc transgenic animals, no increase in Wap RNA abundancy is found during lactation (lane 7). The simultaneous expression of Wap-ras and Wap-myc caused a drastic reduction in the accumulation of $\beta$-casein (Fig. 5A, lane 8) and WAP mRNA (Fig. 5B, lane 8). A weak hybridization signal could be detected only after an exposure 20 times longer. Double transgenic animals were not able to nurse their offspring, which is a reflection of the func- tional impairment caused by the synergism of Wap-ras and Wap-myc expression.

To analyze whether oncogene expression interferes with the transcription or post-transcriptional control of the milk protein genes, we compared their transcription rates in wild-type and double transgenic females. Nuclei were prepared from lactating mammary tissue, and RNA was elongated in vitro in the presence of $\left[{ }^{32}\right.$ P]UTP and hybridized to filter-immobilized DNA of pBR322, the histocompatibility gene $H-2 L^{\mathrm{d}}$, Wap, $\beta$-casein, c-myc, and Ha-ras genes. RNA transcribed in nuclei from wildtype females (Fig. 5D, lane 1) and double transgenic females (lane 2) hybridized equally well to the histocompatibility genes, indicating a comparable efficiency of the in vitro transcription assay. RNA transcribed from nuclei of wild-type females hybridized to $\beta$-casein and only weakly to Wap DNA (lane 1). Transcription of the Wap and the $\beta$-casein genes, as well as that of the Wapmyc and Wap-ras transgenes, was detected in nuclei of double transgenic females (lane 2). The hybridization intensities of the in vitro-elongated RNA to the $\beta$-casein and to the Wap DNA were comparable to those found in the wild-type females and did not reflect the differences found in the cytoplasmic RNA levels. Therefore, we concluded that the transcription rate of the milk protein genes was not affected severely and that the oncogene expression had an effect post-transcriptionally. Although transcribed at a similar rate, milk protein-specific mRNA accumulated at a higher rate in wild-type cells than in oncogene-expressing cells.

\section{Wap-ras, Wap-myc, and tenascin gene expression in mammary tumors of double transgenic animals}

Despite the high number of neoplastic foci persisting in the regressed gland of double transgenic females, palpable mammary tumors developed only after several pregnancies. In all animals, multiple focal tumors were observed 3-4 months after the initial induction of oncogene expression.
Figure 5. Milk protein gene expression in transgenic mice. Five micrograms of cytoplasmic RNA was analyzed on Northern blots with a $\beta$-casein $(A)$ and a Wap-specific $(B)$ probe. (Lanes 1-4) RNA from mammary glands of pregnant females; (lanes 5-8) RNA from mammary glands of lactating females.

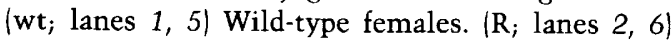
Wap-ras transgenic females. $(M$; lanes 3,7$)$ Wapmyc transgenic females. $\left(\mathrm{MR}_{\text {; }}\right.$ lanes 4,8$)$ Double transgenic females. The positions of $18 \mathrm{~S}$ ribosomal RNA, $\beta$-casein RNA $(A)$, and Wap RNA $(B)$ are indicated. (C) Run-on assays on isolated nuclei from lactating mammary glands of wild-type (lane 1) and double transgenic females (lane 2). In vitro-elongated, ${ }^{32} \mathrm{P}$-labeled transcripts $\left(5 \times 10^{6} \mathrm{cpm}\right)$ were hybridized to nitrocellulose filters containing no DNA $(-)$ or DNA specific for $\mathrm{pBR} 322$, histocompatibility $(\mathrm{H}-2 \mathrm{~L}$ ), Wap, $\beta$-casein ( $\beta$-cas), myc, and ras.

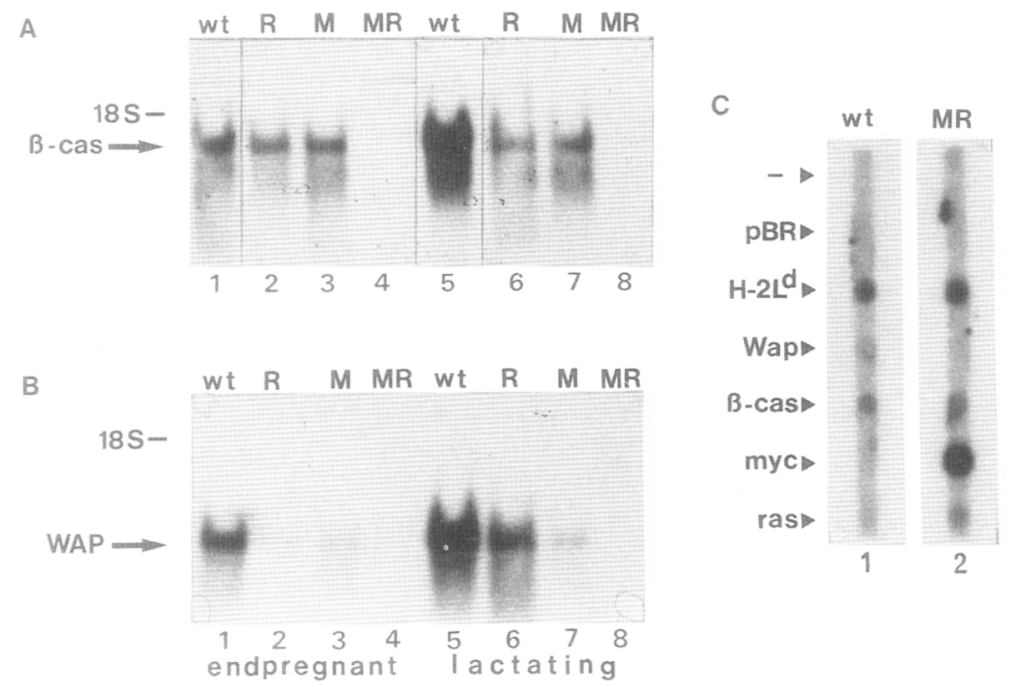


We analyzed the transgene expression in the mammary tumors by RNase protection assays (Fig. 6). Wapmyc (lane 3) expressed at a level similar to that observed in lactating mammary tissue of the same individual (lane 1). The expression of the Wap-ras gene in tumor tissue of double transgenic mice (lane 4) was about 10fold higher than that found in the lactating mammary gland (lane 2). The enhanced Wap-ras expression also was found in mammary tumors of single Wap-ras transgenic mice (Andres et al. 1987; Andres et al., unpubl.).

Strong expression of Wap-myc and Wap-ras mRNA was also found in tumors transplanted into virgin nude mice (Fig. 6, lanes 5 and 6). The maintenance of transgene expression in the absence of lactogenic hormones indicates that the control of Wap promoter utilization found in mammary tissue is abrogated in the transformed cells. Mammary tumors of double transgenic animals share this feature with tumors that occur in Wapras or Wap-myc single transgenic animals (Schönenberger et al. 1988).

The extracellular matrix protein, tenascin, is expressed in mesenchymal cells surrounding the mammary epithelium during fetal development. It is thought to be a morphogenic agent, with its production dependent upon the interaction between epithelial cells and stromal cells. It has been detected also in human and murine mammary tumors (Chiquet-Ehrismann et al. 1986). We analyzed the expression of tenascin in the trangenic mouse tumors, using specific anti-tenascin antibodies in indirect immunofluorescence experiments. No staining was found in lactating mammary gland sections of wild-type animals (not shown). Expression of tenascin could be shown in tumor sections of Wap-myc (Fig. 7A) and double transgenic animals (Fig. 7B). The staining is confined to the mesenchymal cells sur-

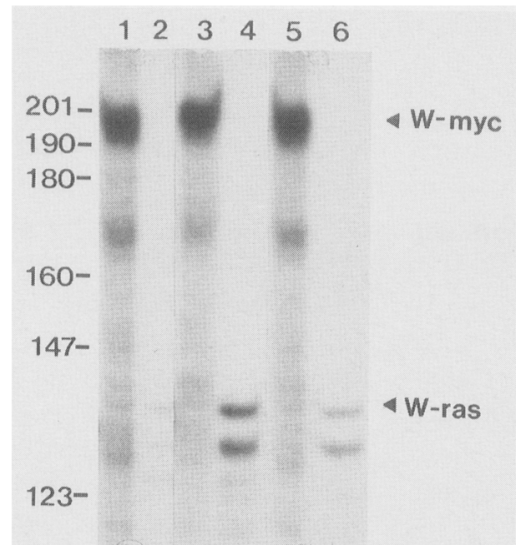

Figure 6. Transgene expression in tumors of double transgenic mice. Ten micrograms of cytoplasmic RNA from lactating mammary gland (lanes 1, 2); tumor tissue (lanes 3, 4); tumor tissue transplanted into a nude mouse (lanes 5,6$)$ were analyzed in RNase protection assays. (Lanes 1, 3, 5) Hybridization to the Wap-myc-specific probe; (lanes 2, 4, 6) hybridization to the Wap-ras-specific probe. HpaIlI-digested, ${ }^{32} \mathrm{P}$-end-labeled pBR322 DNA was used as size marker (indicated in nucleotides). rounding the epithelial compartment of the tumor. Mammary carcinomas derived from Wap-myc transgenic mice were cultured in vitro. Inoculation of a clonal epithelial outgrowth into nude mice resulted in rapid tumor formation. The epithelial cells in these tumors were surrounded by mesenchymal cells of the host (Fig. 7C). Again, tenascin could only be detected in the stromal part of the tumor (Fig. 7D).

Tenascin expression provides an interesting example for the interaction between transformed epithelial cells and the surrounding stroma. Oncogene-expressing tumor cells induced the normal stromal cells to express tenascin. Tenascin expression, in turn, might influence the morphology and growth properties of the transformed epithelial cells.

\section{Discussion}

The development of the mammary epithelium during pregnancy to the differentiated lactational state involves cellular proliferation, lobulo-alveolar organization, and the acquisition of the potential to express the milk-specific protein genes. These developmental processes are distinctly impaired by the expression of the Ha-ras or c-myc oncogenes before tumors arise.

The targeting of activated Ha-ras expression to the mammary epithelial cells does not prevent the cells from reaching an end-differentiated state during lactation. The differentiation-specific gene expression of the $\beta$-casein and the Wap gene, however, is strongly reduced in Wap-ras-expressing cells. Because the mammary glands are nearly normal in their morphology, this reduction may reflect interference of Wap-ras with specific gene expression. A similar effect of the Ha-ras oncogene has been observed in cultured myoblasts. Expression of the mutated Ha-ras oncogene abolished the expression of differentiation-specific genes without inducing myoblast proliferation (Payne et al. 1987). Expression of a conditional MMTV LTR-Ha-ras oncogene represses glucocorticoid-regulated gene expression in NIH-3T3 cells (Jaggi et al. 1986). The reduced expression of milk protein gene expression in the Wap-ras transgenic animals may reflect an impaired responsiveness to the lactogenic hormones.

Expression of Wap-myc in the mammary epithelium causes an incomplete alveolar development during lactation. The Wap-myc gene expression also causes continued cell proliferation during lactation and even postlactationally. These observations can be interpreted as a block in the differentiation pathway after the onset of Wap-myc expression. Consequently, the cells do not reach a fully differentiated stage that allows maximum milk protein gene expression. $\mathrm{v}-\mathrm{myc}$ expression in cultured mammalian epithelial cells does not impair $\beta$-casein induction by lactogenic hormones (Ball et al. 1988). Conceivably, Wap-myc expression does not interfere with the signals generated by the lactogenic hormones and the induction of milk protein gene expression. Correlations between myc expression, proliferation, and differentiation have been found consistently in many dif- 

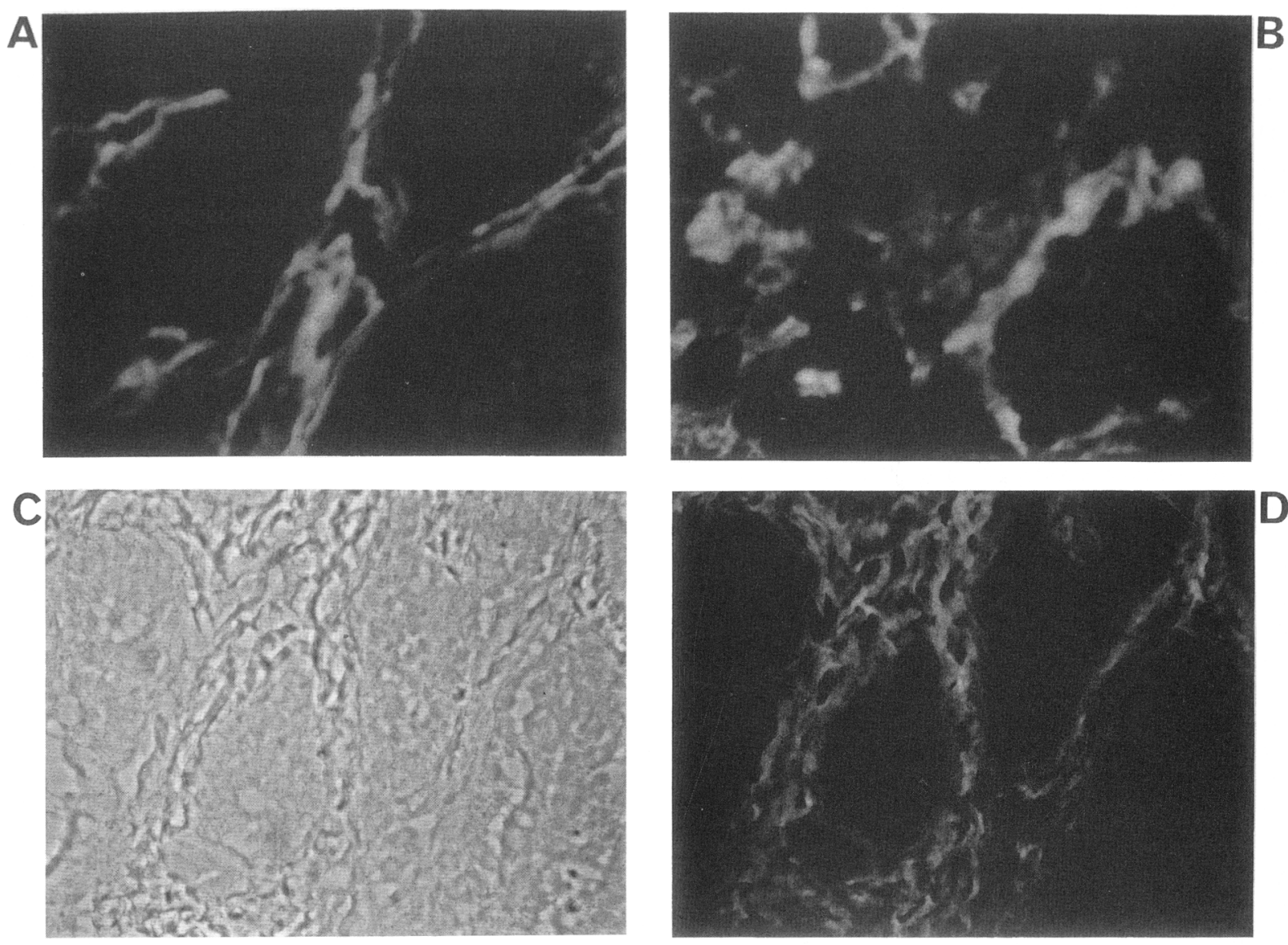

Figure 7. Detection of tenascin in tumors and mammary glands. Frozen sections were analyzed by indirect immunofluorescence staining using an anti-tenascin antibody and a FITC-labeled anti-rabbit antibody. $(A)$ Tumor section of a Wap-myc transgenic female; $(B)$ tumor section of a double transgenic female; $(C)$ phase-contrast view of a section through a nude mouse tumor; $(D)$ immunofluorescence of the same section. Magnification, $540 \times$.

ferent cultured cell types (Alema et al. 1985; Endo and Nadal-Ginard 1986; Yokoyama and Imamoto 1987). The constitutive expression of the $\mathrm{E} \mu-m y c$ hybrid gene retarded differentiation of the pre-B cells without grossly interfering with their immunological function in transgenic mice (Vaux et al. 1987).

The phenotype of the epithelial cells in the double transgenic animals represents the added effects of both oncogenes, leading to the very low $\beta$-casein and Wap mRNA levels observed in double transgenic animals. Selective stabilization of $\beta$-casein mRNA appears to be an important mechanism for its high accumulation (Rosen et al. 1980). Our data implicate a similar mechanism for the control of the Wap gene expression. Although regulated by the same promoter, endogenous Wap expression was reduced, whereas Wap-ras and Wap-myc expression was high in the double transgenic animals. The potential of mammary epithelial cells for utilizing the Wap gene promoter leads to the activation of the endogenous Wap gene, as well as that of the transgenes. Because of the divergent sequences of the Wap gene and the oncogenes, the selective post-transcriptional control during advanced cell differentiation is only effective for the Wap gene expression. The selective stabilization of $\beta$-casein mRNA is mediated mainly by prolactin (Hobbs et al. 1982). Both oncogenes might impair prolactin action synergistically. Wap-myc expression may keep the cells from becoming fully responsive to the high levels of prolactin during end pregnancy and lactation. In addition, Wap-ras may interfere with the prolactin-mediated stabilization pathway leading to the rapid degradation of the Wap and $\beta$-casein mRNA.

The histological appearance of mammary glands from single and double transgenic females allows insights into the mechanisms of oncogene action. The persistence of proliferating epithelial cells in mammary glands of Wap-myc transgenic mice might provide a reservoir of cells in which additional mutations can occur and tumorous growth might originate. Wap-ras expression is not a mitogenic stimulus in differentiating mammary epithelial cells that did not persist postlactationally. This might decrease the chance to accumulate additional mutations required for transformation, leading to the low incidence of mammary tumors. A different result was observed in transgenic mice expressing a MMTV LTR-v-Ha-ras hybrid gene (Sinn et al. 1987). Mammary gland tumors occurred with a high frequency. In contrast to the Wap promoter, the LTR is expressed in mammary epithelial cells at earlier stages of development. The oncogenic effects of the Ha-ras gene may be a 
function of the differentiation state of a cell. An analysis of the effect of the ras oncogene in the embryonal carcinoma cell line P19 showed that the fibroblast cell lineage was transformed only when the oncogene was expressed during early stages of development (Bell et al. 1986). Hyperplastic lesions, which are likely to represent prestages of tumors, persist with a high frequency in the regressed mammary glands of double transgenic females. The abundant occurrence of these lesions might reflect cooperativity of Wap-ras and Wap-myc in the transformation process. However, palpable tumors occur focally and only after several pregnancies. This clearly indicates that coexpression of Wap-ras and Wap-myc is not sufficient to cause the fully malignant phenotype.

Properties, which are unique to the tumors, indicate the occurrence of additional mutations in the oncogeneexpressing mammary epithelial cells. First, tumor formation in all transgenic mice is accompanied by a lactogenic hormone-independent transcription of the Wap promoter. This release is a transformation-specific characteristic, because oncogene expression, by itself, as it occurs in lactating mammary gland cells, is not sufficient to cause this deregulation. We suggest that constitutive, lactogenic hormone-independent oncogene expression is required for tumor growth. The time required for such a cell to emerge is reflected by the tumor latency. This latency period is comparable in double transgenic and single transgenic Wap-myc animals. The cooperation of Wap-ras and Wap-myc is probably not involved in the establishment of the malignant, hormoneindependent phenotype of the tumors. The requirement for a transition to a hormone-independent state is the main difference between the double transgenic model described here and the experimental system described by Sinn et al. (1987). The glucocorticoid-dependent MMTV promoter allows expression of the LTR-myc and the LTR-ras oncogene early in development and independent of the lactogenic stimulus. A clear cooperation of the myc and ras genes in mammary tumor formation was found in LTR-myc, LTR-ras double transgenic mice. This was reflected by a reduced latency and the occurrence of mammary tumors in male animals.

Second, tumor formation in double transgenic females is always accompanied by increased levels of the Wapras mRNA. This is also true for the mammary and parotid tumors that develop in Wap-ras single transgenic mice (Andres et al. 1987; Groner et al. 1988). Increasing the amount of ras expression might be an important event in the carcinogenesis. Recently, Kelekar and Cole (1987) showed that the high levels of Ha-ras expression required to transform baby rat kidney cells could not be substituted for by c-myc oncogene expression. Similarly, our results suggest that an increase in the Wap-ras expression is still a prerequisite for the development of the fully malignant phenotype, despite the coexpression of the ras and myc oncogenes.

Third, malignant tumor cells acquire the capacity to interact with the surrounding normal tissue. The induction of tenascin in surrounding normal stromal cells might influence the morphology and growth character- istics of the transformed epithelial cells (Chiquet-Ehrismann et al. 1986). The high induction of tenascin in the stroma was not observed in lactating glands of single and double transgenic animals even after several pregnancies. The induction of tenascin is confined to tumors and might be the consequence of events that finally convert the cells to the fully malignant phenotype.

\section{Methods}

\section{Establishment of double transgenic animals}

The establishment of single transgenic mice bearing the Wapras or Wap-myc hybrid gene was described previously. The founder animals represent the $F_{1}$ generation of C57B16 $\times$ SJL hybrid crosses. Heterozygous animals from the Wap-ras transgenic line 3 or 58 were crossed with heterozygous Wap-myc transgenic animals from line 33 . The resulting progeny were analyzed for the presence of both oncogenes, as described (Andres et al. 1987; Schönenberger et al. 1988).

\section{Histological procedures}

Mammary glands were stretched on parafilm and fixed in a mixture of ethanol, acidic acid formaline, saline (Harrison 1984) and embedded in Histowax tissue-embedding medium (Histo-Lab, Ltd.). Sections $(5 \mu \mathrm{m})$ were stained in haematoxylin-eosin, periodic acid Schiff, Ziehl-Nielsen, or elastin-van Gieson.

\section{RNA analysis}

Total cytoplasmic RNA was prepared as described (Andres et al. 1987). RNase protection assays were carried out essentially according to Melton et al. (1984). Ten micrograms of total RNA was hybridized to a single-stranded ${ }^{32} \mathrm{p}$-labeled antisense probe specific for exon 1 of the Wap-ras gene or the Wap-myc gene. After subsequent RNase treatment, a protected fragment of 143 nucleotides is indicative of Wap-ras RNA (Andres et al. 1987). A protected fragment of 198 nucleotides is indicative for Wapmyc transcripts (Schönenberger et al. 1988). The probe used to detect Wap-ras transcripts in Figure 1 is a SmaI-Pst I fragment comprising exon 1 of the human Ha-ras gene /Capon et al. 1983). The protected fragment comprises the 133 nucleotides of ras sequences in exon 1 of the Wap-ras gene.

The RNA blots were done according to Thomas et al. (1980). A 510-bp EcoRI restriction fragment of the $\beta$-casein cDNA insert of pA200 was used as probe to detect $\beta$-casein sequences. The 450-bp Wap cDNA insert of pA182 was used as the Wapspecific probe. Both plasmids were obtained from L. Hennighausen (Bethesda).

\section{Nuclear transcription analysis}

Nuclei were isolated from mammary glands according to McKnight and Palmiter (1979), suspended in $50 \mathrm{~mm}$ Tris (pH 8.3), $5 \mathrm{mM} \mathrm{MgCl}_{2}, 0.1 \mathrm{mM}$ EDTA, and $43.5 \%$ glycerol at a concentration of $1.2 \mathrm{mg} \mathrm{DNA} / \mathrm{ml}$, and stored at $-70^{\circ} \mathrm{C}$. The run-on transcription assay was done essentially as described (McKnight and Palmiter 1979). Approximately $2 \times 10^{7}$ nuclei were incubated in $150 \mathrm{mM} \mathrm{KCl}, 3 \mathrm{mM} \mathrm{MgCl}_{2}, 5 \mathrm{~mm}$ dithiothreitol (DTT), 30 units of RNasin, $1 \mathrm{mM} \mathrm{ATP,} \mathrm{GTP,} \mathrm{and} \mathrm{CTP,}$ and $50 \mu \mathrm{Ci}\left[{ }^{32} \mathrm{P}\right] \mathrm{UTP}(400 \mathrm{Ci} / \mathrm{mmole})$ in a final volume of $100 \mu \mathrm{l}$ for $20 \mathrm{~min}$ at $26^{\circ} \mathrm{C}$. After DNase and proteinase $\mathrm{K}$ treatment, the in vitro-elongated RNA was purified from unincorporated [32P]UTP by several ethanol precipitations. DNA (1 $\mu \mathrm{g})$ was im- 
mobilized on nitrocellulose filters. The in vitro-elongated RNAs, representing $5 \times 10^{6}$ to $10 \times 10^{6} \mathrm{cpm}$ were hybridized to these filter strips for 3 days in $50 \%$ formamide and $2 \times$ SSC at $37^{\circ} \mathrm{C}$.

\section{Immunofluorescence}

Thin, frozen sections $(6 \mu \mathrm{m})$ were fixed for 3-5 min in ice-cold methanol/acetone $(1: 1)$ and air-dried for $30 \mathrm{~min}$. The sections were incubated in anti-tenascin serum and diluted $1: 50$ with phosphate-buffered saline (PBS) for $1 \mathrm{hr}$ at $37^{\circ} \mathrm{C}$. The anti-tenascin serum was kindly provided by $\mathrm{R}$. Chiquet-Ehrismann (Basel). After washing with PBS, the sections were incubated for $1 \mathrm{hr}$ at $37^{\circ} \mathrm{C}$ with a fluorescein-isothiocyanate (FITC)-conjugated goat anti-rabbit antibody (Cappel Laboratories). After rinsing with $\mathrm{PBS}$, the sections were mounted under coverslips with $15 \%$ mowiol, $50 \mathrm{mg} / \mathrm{ml}$ of diazabicyclo(2.2.2)octan.

\section{Acknowledgments}

We thank Drs. N.E. Hynes and E. Lucassen (Bern) for critical comments on the manuscript. The technical assistance of $\mathrm{L}$. Kuyper-Pietersma, E. van Muylwÿk, and I. Bulthuis (Amsterdam), and the editorial assistance of C. Wiedmer and T. Diabaté (Bern) are gratefully acknowledged.

\section{Note added in proof}

Restriction enzyme analysis of the Wap-ras transgene in animals used for the experiments has shown that the pattern does not correspond exactly to the expected fragment size deduced from the construct shown in Figure 1 in Andres et al. (1987). This discrepancy does not affect the hormone-dependent and tissue-specific expression of the Wap-ras gene at the level of RNA and p21 human Ha-ras.

\section{References}

Adams, J.M., A.W. Harris, C.A. Pinkert, L.M. Corcoran, W.S. Alexander, S. Cory, R.D. Palmiter, and R.L. Brinster. 1985. The $c-m y c$ oncogene driven by immunoglobulin enhancers induces lymphoid malignancy in transgenic mice. Nature 318: $533-538$.

Alema, S., F. Tato, and D. Boettiger. 1985. myc and src oncogenes have complementary effects on cell proliferation and expression of specific extracellular matrix components in definitive chondroblasts. Mol. Cell. Biol. 5: 538-544.

Andres, A.-C., C.-A. Schönenberger, B. Groner, L. Hennighausen, M. LeMeur, and P. Gerlinger. 1987. Ha-ras oncogene expression directed by a milk protein gene promoter: Tissue specificity, hormonal regulation, and tumor induction in transgenic mice. Proc. Natl. Acad. Sci. 84: 1299- 1303.

Ball, R.K., A. Ziemiecki, C.-A. Schönenberger, E. Reichmann, S.M.S. Redmond, and B. Groner. 1988. v-myc alters the response of a cloned mouse mammary epithelial cell line to lactogenic hormones. Mol. Endocrinol. 2: 133-142.

Banerjee, M.R. 1976. Responses of mammary cells to hormones. Int. Rev. Cytol. 47: 1-97.

Cell, J.C., K. Jardine, and M.W. McBurney. 1986. Lineage-specific transformation after differentiation of multipotential murine stem cells containing a human oncogene. Mol. Cell. Biol. 6: 617-625.

Berger, M., G. Locher, S. Saurer, W. Gullick, M. Waterfield, B. Groner, and N.E. Hynes. 1988. c-erbB2 gene amplification and protein expression in human breast carcinomas corre- late with nodal status and nuclear grading. Cancer Res. 48: $1238-1243$.

Bishop, J.M. 1985. Trends in oncogenes. Trends Genet. 1: 245249.

Capon, D.J., E.Y. Chen, A.D. Levinson, P.H. Seeburg, and D.V. Goeddel. 1983. Complete nucleotide sequences of the T24 human bladder carcinoma oncogene and its normal homologue. Nature 302: 33-37.

Chiquet-Ehrismann, R., E.J. Mackie, C.A. Pearson, and T. Sakakura. 1986. Tenascin: An extracellular matrix protein involved in tissue interactions during fetal development and oncogenesis. Cell 47: 131-139.

Endo, T. and B. Nadal-Ginard. 1986. Transcriptional and posttranscriptional control of $c-m y c$ during myogenesis: Its mRNA remains inducible in differentiated cells and does not suppress the differentiated phenotype. Mol. Cell. Biol. 6: $1412-1421$.

Escot, C., C. Theillet, R. Lidereau, F. Spyratos, M.H. Champeme, J. Gest, and R. Collaban. 1986. Genetic alterations of the c-myc protooncogene in human primary breast carcinomas. Proc. Natl. Acad. Sci. 83: 4834-4838.

Groner, B., N.E. Hynes, S. Kozma, S.M.S. Redmond, S. Saurer, M. Schmitt-Ney, R. Ball, E. Reichmann, C.-A. Schönenberger, and A.-C. Andres. 1988. Identification of oncogenes in breast tumors and their effect on growth and differentiation. In Breast cancer, cellular and molecular biology led. M.E. Lippman and R. Dickson). Martinus Nijhoff, Boston, Massachusetts. (in press.)

Harrison, P.T.C. 1984. An ethanol-acetic acid-formol saline fixative for routine use with special application to the fixation of non-perfused rat lung. Lab. Anim. 18: 325-331.

Hobbs, A.A., D.A. Richards, D.J. Kessler, and J.M. Rosen. 1982. Complex hormonal regulation of rat casein expression. $I$. Biol. Chem. 257: 3598-3605.

Jaggi, R., B. Salmons, D. Muellener, and B. Groner. 1986. The $\mathrm{v}$-mos and Ha-ras oncogene expression represses glucocorticoid hormone-dependent transcription from the mouse mammary tumor virus LTR. EMBO J. 5: 2609-2616.

Kelekar, A. and M.D. Cole. 1987. Immortalization by c-myc, Ha-ras, and Ela oncogenes induces differential cellular gene expression and growth factor responses. Mol. Cell. Biol. 7:3899-3907.

Khillan, J.S., M.K. Oskarsson, F. Probst, T. Kuwabara, G.F. Vande Woude, and H. Westphal. 1987. Defects in lens fiber differentiation are linked to c-mos overexpression in transgenic mice. Genes Dev. 1: 1327-1335.

Kozma, S., M.E. Bogaard, K. Buser, S. Saurer, J.C. Bos, B. Groner, and N.E. Hynes. 1987. The human c-Kirsten ras gene is activated by a novel mutation in codon 13 in the breast carcinoma cell line MDA-MB 231. Nucleic Acids Res. 15: 59635971.

Kratochwil, K. 1969. Organ specificity in mesenchymal induction demonstrated in the embryonic development of the mammary gland of the mouse. Dev. Biol. 20: 46-71.

Langdon, W.Y., A.W. Harris, S. Cory, and J.M. Adams. 1986. The c-myc oncogene perturbs B lymphocyte development in E $\mu$-myc transgenic mice. Cell 47: 11-18.

Leder, A., P.K. Pattengale, A. Kuo, T.A. Stewart, and P. Leder. 1986. Consequences of widespread deregulation of the c-myc gene in transgenic mice: Multiple neoplasm and normal development. Cell 45: 485-495.

Levine, J.F. and F.F. Stockdale. 1985. Cell interactions promote mammary epithelial cell differentiation. J. Cell. Biol. 100: $1415-1422$.

McKnight, G.S. and R.D. Palmiter. 1979. Transcriptional regulation of the ovalbumin and conalbumin genes by steroid 
hormones in chick oviduct. J. Biol. Chem. 254: 9050-9058.

Melton, D.A., P.A. Krieg, M.R. Rebagliati, T. Maniatis, K. Zinn, and M.R. Green. 1984. Efficient in vitro synthesis of biologically active RNA and RNA hybridization probes from plasmids containing a bacteriophage kSP6 promoter. $\mathrm{Nu}$ cleic Acids Res. 12: 7035-7056.

Payne, P.A., E.N. Olson, P. Hsiau, R. Roberts, M.B. Perryman, and M.D. Schneider. 1987. An activated c-Ha-ras allele blocks the induction of muscle-specific genes whose expression is contingent on mitogen withdrawal. Proc. Natl. Acad. Sci. 84: 8956-8960.

Quaife, C.J., C.A. Pinkert, D.M. Ornitz, R.D. Palmiter, and R.L. Brinster. 1987. Pancreatic neoplasia induced by ras expression in acinar cells of transgenic mice. Cell 48: 1023-1034.

Rosen, J.M., R.J. Matusik, D.A. Richards, P. Gupta, and J.R. Rodgers. 1980. Multihormonal regulation of casein gene expression at the transcriptional and posttranscriptional levels in the mammary gland. Recent Prog. Horm. Res. 36: 157193.

Rüther, U., Ch. Garber, D. Komitowski, R. Müller, and E.F. Wagner. 1987. Deregulated c-fos expression interferes with normal bone development in transgenic mice. Nature 325: $412-416$.

Schönenberger, C.-A., A.-C. Andres, B. Groner, M. Van der Valk, M. LeMeur, and P. Gerlinger. 1988. Targeted c-myc gene expression in mammary glands of transgenic mice induces mammary tumors with constitutive milk protein gene transcription. EMBO I. 7: 169-175.

Sinn, E., W. Muller, P. Pattengale, I. Tepler, R. Wallace, and P. Leder. 1987. Coexpression of MMTV/v-Ha-ras and MMTV/ c-myc genes in transgenic mice: Synergistic action of oncogenes in vivo. Cell 49: 465-475.

Slamon, D.J., G.M. Clark, S.G. Wong, W.J. Levin, A. Ullrich, and W.L. McGuire. 1987. Human breast cancer: Correlation of relapse and survival with amplification of the HER-2/neu oncogene. Science 235: 177-182.

Stewart, T.A., P.K. Pattengale, and P. Leder. 1984. Spontaneous mammary adenocarcinomas in transgenic mice that carry and express MTV/myc fusion genes. Cell 38: 627-637.

Struhl, K. 1987. The DNA-binding domains of the jun oncoprotein and the yeast GCN4 transcriptional activator protein are functionally homologous. Cell 50: 841-846.

Suda, Y., S. Aizawa, S. Hirai, I. Inoue, Y. Furita, M. Suzuki, S. Hirohashi, and Y. Ikawa. 1987. Driven by the same Ig enhancer and SV40 promoter ras induced lung adenomatous tumors, myc induced pre-B cell lymphomas and SV40 large $\mathrm{T}$ gene a variety of tumors in transgenic mice. EMBO $\mathrm{I}$. 6: 4055-4065.

Thomas, P. 1980. Hybridization of denatured RNA and small DNA fragments transferred to nitrocellulose. Proc. Natl. Acad. Sci. 77: 5201-5205.

Varley, J.M., J.E. Swallow, W.J. Brammer, J.L. Whittaker, and R.A. Walker. 1987. Alterations to either c-erbB-2(neu) or c-myc proto-oncogenes in breast carcinomas correlate with poor short-term prognosis. Oncogene 1: 423-430.

Vaux, D.L., J.M. Adams, W.S. Alexander, and B.L. Pike. 1987. Immunologic competence of B cells subjected to constitutive c-myc oncogene expression in immunoglobulin heavy chain enhancer myc transgenic mice. I. Immunol. 139: 3854-3860.

Yokoyama, K. and F. Imamoto. 1987. Transcriptional control of the endogenous myc protooncogene by antisense RNA. Proc. Nat1. Acad. Sci. 84: 7363-7367.

Zarbl, H., S. Sukumar, A.V. Arthur, D. Martin-Zanca, and M. Barbacid. 1985. Direct mutagenesis of Ha-ras-1 oncogenes by $\mathrm{N}$-nitroso- $\mathrm{N}$-methylurea during initiation of mammary carcinogenesis in rats. Nature 315: 382-385. 


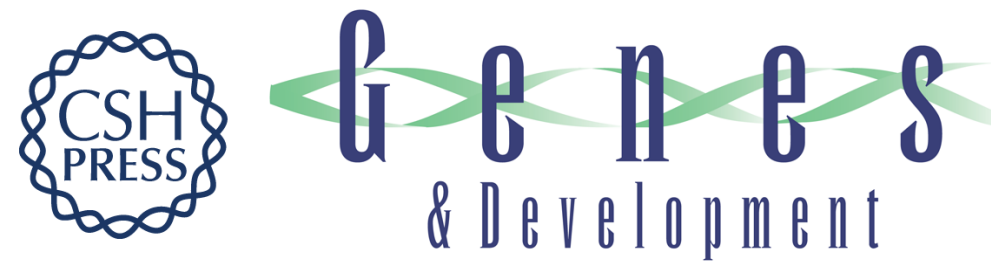

\section{Ha-ras and c-myc oncogene expression interferes with morphological and functional differentiation of mammary epithelial cells in single and double transgenic mice.}

A C Andres, M A van der Valk, C A Schönenberger, et al.

Genes Dev. 1988, 2:

Access the most recent version at doi:10.1101/gad.2.11.1486

References This article cites 39 articles, 16 of which can be accessed free at:

http://genesdev.cshlp.org/content/2/11/1486.full.html\#ref-list-1

License

Email Alerting

Service

Receive free email alerts when new articles cite this article - sign up in the box at the top right corner of the article or click here.

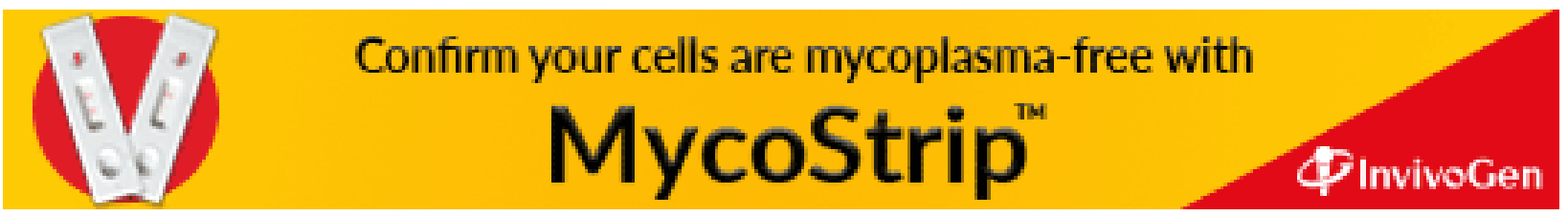

